\title{
Forecasting Inflation Rate (WPI \&CPI) in India with Time Series Model - A Statistical Recurrent Neural Network Approach
}

\author{
P. Laxmi Prasanna \\ Assistant Professor, Department of Mathematics and Statistics, RBVRR Women's College, Narayanaguda, Hyderabad
}

\begin{abstract}
In this paper, recent years neural networks have received an increasing amount of attention among macroeconomic forecasters. India has experienced persistently high inflation in recent years, despite a period of belowtrend economic growth. The two main factors of inflation in India are the Wholesale Price Index (WPI) and the Consumer Price Index (CPI). Inflation rates in India are usually quoted as changes in the Wholesale Price Index for all commodities. The WPI and CPI data used for estimating the models for the period Jan 2016 to Dec 2020. However, various tests indicate that there is little evidence that the improvement in forecasting accuracy is statistically significant. The absolute mean error and mean absolute percent error were also lower for the neural network models. RMSE, MAE and MAPE are used for the comparison of the models. Result of this study shows that RNN is performing better than the other models ARIMA in forecasting the Inflation rate in India.
\end{abstract}

Keywords: ARIMA, Neural networks, RNN, Inflation, WPI, CPI, Root Mean Squared Error (RMSE), Mean Absolute Error (MAE), and Mean Absolute Percentage Error (MAPE).

\section{INTRODUCTION}

Macro econometrics is a branch of the econometrics field that studies how the aggregate economy behaves. In Macro econometrics a variety of econometrics - wide phenomena is thoroughly examined such as Inflation, price levels, rate of growth, national income, gross domestic product and changes in un-employment. It is Concerned with the behavior of the Economy as a whole with recessions and booms. The Economy's total output of goods and services. The growth of output, the rates of inflation and the un - Employment. The balance of payments and Exchange rates. Macroeconomics deals with both long run economic growth and the short run fluctuations that constitute the business cycle. Inflation, Growth, and Unemployment are related through the business cycle. The Consumer Price Index (CPI) measures the cost of buying a fixed basket of goods and services representative of the Purchases of urban consumers. The CPI differs in three main ways from the GDP deflator, first the deflator measures the prices of a much wider group of goods than the CPI does, second the CPI measures the cost of a given basket of goods which is the same from year to year, The basket of goods included in the GDP deflator, however it is differs from year to year depending on what is produced in the economy in each year. Third the CPI directly includes prices of imports, where as the deflator includes only prices of goods produced in the United states.

\section{ARIMA}

It stands for Autoregressive Integrated Moving Average models. Univariate (Single Vector) ARIMA is a forecasting technique that projects the future values of a series based entirely on its own inertia

RMSE

The Root Mean Square Deviation (RMSD) or Root Mean Square Error (RMSE) is a frequently used measure of the differences between values (sample and population values) predicted by a model or an estimator and the values actually observed

MAPE

The Mean Absolute Percentage Error (MAPE) also known as Mean Absolute Percentage Deviation (MAPD) is a measure of prediction accuracy of a forecasting method in statistics. It usually expresses accuracy as a percentage, and is defined by the formula

$$
\mathrm{M}=\frac{100}{n} \sum_{t=1}^{n}\left|\frac{A_{t}-F_{t}}{A_{t}}\right|
$$

Where $A_{t}$ is the actual value and $F_{t}$ is the forecast value

The difference between $A_{t}$ and $F_{t}$ is divided by the actual value $A_{t}$ again. The absolute value in this calculation is summed for every forecasted point in time and divided by the number of fitted points $\mathrm{n}$. multiplying by 100 makes it a percentage error. 


\section{International Advanced Research Journal in Science, Engineering and Technology}

Vol. 8, Issue 6, June 2021

DOI: 10.17148/IARJSET.2021.8616

\section{Neural Networks}

Neural networks are unable to out perform a naïve approach no change model. More pronounced non- linearities at the longer horizon is consistent with the possible asymmetric effects of monetary policy on the real economy.

Neural networks are made up of many artificial neurons. A neuron can have any no. of inputs from 1 to $\mathrm{n}$, where $\mathrm{n}$ is the total no. of inputs. The inputs may be represented therefore as $\mathrm{X}_{1}, \mathrm{X}_{2}, \ldots \mathrm{X}_{\mathrm{n}}$. and the corresponding weights for the inputs as $\mathrm{W}_{1}, \mathrm{~W}_{2}, \ldots \mathrm{W}_{\mathrm{n}}$.

\section{Feed Forward Network}

The neurons in each layer feed their output forward to the next layer until we get the final output from the neural networks. There can be any no. of hidden layers with in a feed forward network. The no. of neurons can be completely arbitrary.

Multi - Layer Perceptron (MLP)

Multi - Layer Perceptron is implemented describe any general feed forward (no recurrent connections) network environment exist for the variables considered.

\section{LITERATURE REVIEW}

The Literature Review on ARIMA model and Artificial Neural Network

Moumita Sarkar (2019): In this paper he tells about an advancement of artificial neural network functioning, Deep learning as a successor of ANN, applications of neural network in different areas and finally its fulfillment of challenges have been discussed

Zineb Aman (2018): In this paper he forecast the future demand in a food company and he used to develop the ARIMA model by using Box-Jenkins method and also estimated different methods are Bayesian criterion, MLE, and Standard Error.

Dr.S.A. Jyothi Rani, Prof. VV Haragopal, and Prof. M.Krishna Reddy (2017): In this they studied about forecasting inflation rate of India using by Neural networks. This paper outlines to forecast monthly Inflation rate of India by using Neural Networks. The data is used for estimating the models for the period of July 1994 to March 2008. In this analysis RNN is better than the BPN (Back Propagation Network) model

Prapanna Mondal (2014): In this Paper he studied Effectiveness of Time Series forecasting the stock prices using ARIMA model. His analysis is on fifty six Indian stocks from seven sectors. All the stocks that are listed in National Stock Exchange (NSE)

\section{OBJECTIVES OF THE STUDY}

1. To improve the accuracy of CPI and WPI forecasts of certain banks GDP output growth by using leading indicator neural network models and compare with ARIMA.

2. To fit the best model using ARIMA, RNN, and MLP with monthly WPI and CPI data using python code.

3. To find the MSE, RMSE, and MAPE values for the models ARIMA, RNN, and MLP.

4. To forecast the monthly WPI and CPI data for next 5 years using the best model from the given models in our study.

\section{RESEARCH METHODOLOGY}

To fit an ARIMA model, RNN model, and MLP model. In this study, we collected data from Reserve Bank of India (RBI) for wholesale price Index (WPI) and consumer price index(CPI) data from 2016 to 2020 monthly taken. Using Python code, we obtain following results along with diagrams.

SARIMAX Results

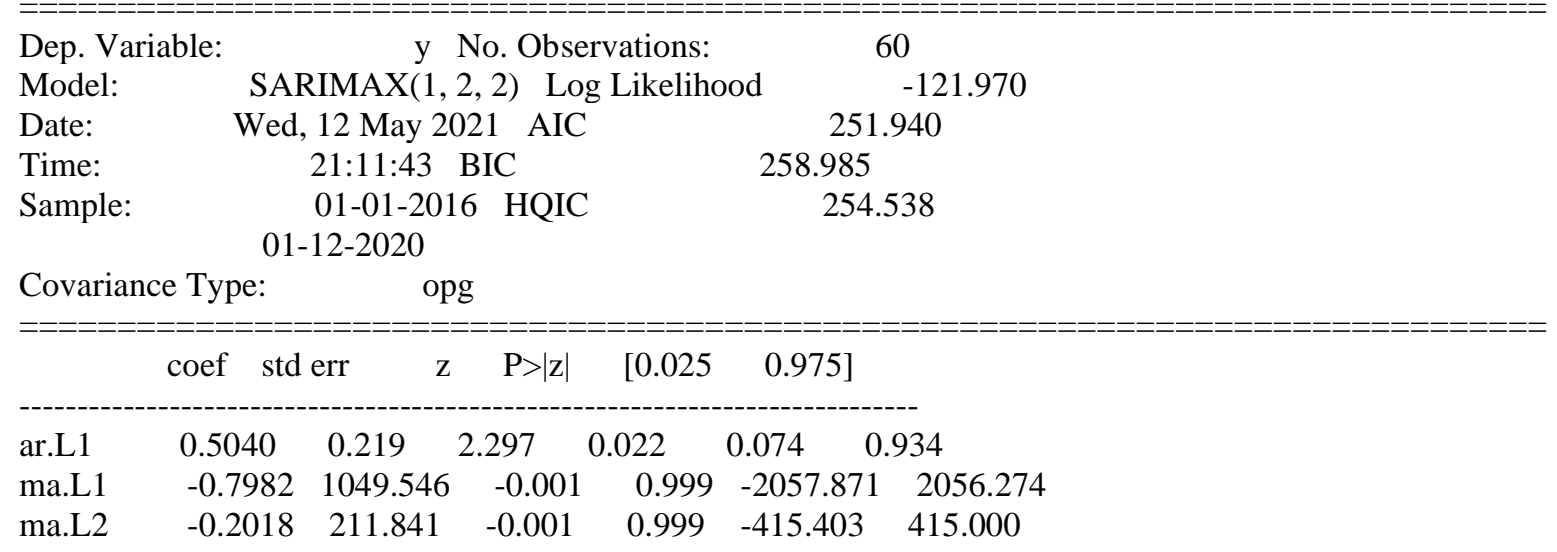




\section{International Advanced Research Journal in Science, Engineering and Technology}

Vol. 8, Issue 6, June 2021

DOI: $10.17148 / I A R J S E T .2021 .8616$

$\begin{array}{lllllll}\text { sigma2 } & 16.0222 & 1.68 \mathrm{e}+04 & 0.001 & 0.999 & -3.29 \mathrm{e}+04 & 3.3 \mathrm{e}+04\end{array}$

\begin{tabular}{lccc}
$===========================================$ \\
Ljung-Box (L1) (Q): & \multicolumn{2}{c}{0.02 Jarque-Bera (JB): } & 8.55 \\
Prob(Q): & 0.89 Prob(JB): & 0.01 \\
Heteroskedasticity (H): & 0.17 Skew: & 0.70 \\
Prob(H) (two-sided): & 0.00 Kurtosis: & 4.68
\end{tabular}

Plot - Diagnostic
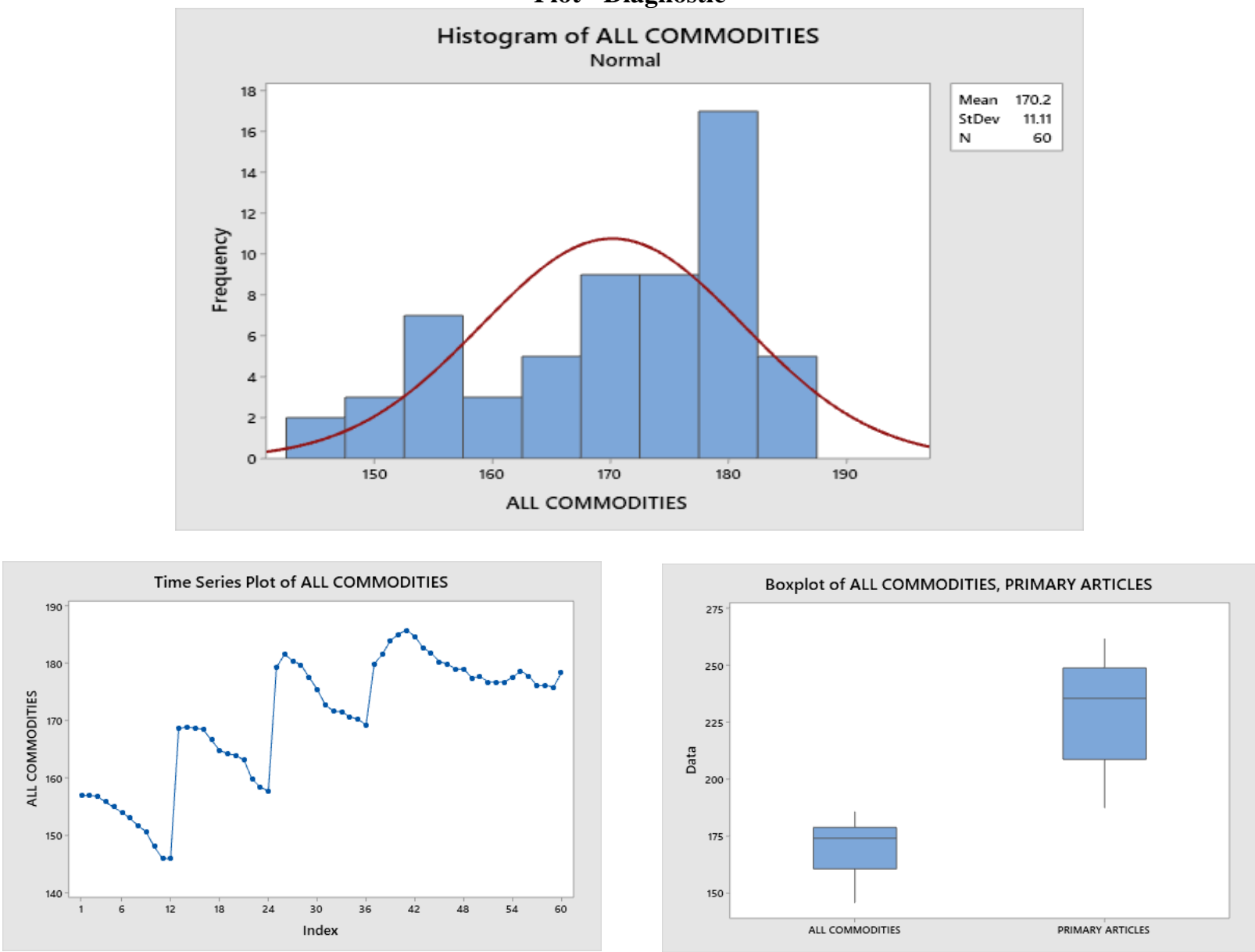

\section{CONCLUSION}

Test Accuracy

\begin{tabular}{|c|c|c|c|}
\hline & ARIMA & MLP & RNN \\
\hline MSE & 536.78963 & 2789.4563 & 280.765 \\
\hline RMSE & 23.16872 & 52.8153 & 16.75604 \\
\hline MAPE & 22.16872 & 0.981066 & 0.9403 \\
\hline
\end{tabular}

From the above table Test of accuracy is given from the above models based on these errors- Mean square error(MSE), Root mean square error(RMSE), and Mean absolute percentage error (MAPE) From the above table we observe that comparing to Mean square error(MSE), Root mean square error (RMSE), and Mean absolute percentage error(MAPE). The RNN is better than the other ARIMA and MLP models. We observe least error in RNN model.

The forecasted of WPI and CPI inflation in India from 2021 to 2025

\begin{tabular}{|l|l|l|l|l|l|}
\hline year & $\mathbf{2 0 2 0 - 2 1}$ & $\mathbf{2 0 2 1 - 2 2}$ & $\mathbf{2 0 2 2 - 2 3}$ & $\mathbf{2 0 2 3 - 2 4}$ & $\mathbf{2 0 2 4 - 2 5}$ \\
\hline WPI (\%) & 10.4 & 12.3 & 11.1 & 12.4 & 13.5 \\
\hline CPI (\%) & 4.4 & 5.1 & 4.2 & 5.2 & 4.3 \\
\hline
\end{tabular}




\section{International Advanced Research Journal in Science, Engineering and Technology}

Vol. 8, Issue 6, June 2021

\section{DOI: $10.17148 /$ IARJSET.2021.8616}

\section{REFERENCES}

1. Box, G.E.PG.M. Jenkins and Reinsel, G.C.(2009): “Time series analysis: Forecasting and control”, Third Edition, Pearson publications.

2. S.S. Haykin, 1994. Neural Network: A Comprehensive foundation. Macmillian college publishing company, Newyork

3. Aminian, F., Suarex, E.D., Aminian,M., and Walz, D.t.(2006), forecasting Economic data with Neural Networks, Computational Eco, 28, 71-78

4. Kishnamurthy, K.(2002), Macroeconometrics models for India: past, present and prospects. Economic political weekly, XXXVV(42), $4295-4308$.

5. Kuan, C. and white, H. (1994), artificial neural networks: an econometric perspective, Econometric Review,13(NOV) 